\title{
Apontamentos historiográficos sobre o livro didático de português: o controle governamental em foco
}

Wesley Luis Carvalhaes"

\section{Resumo}

Este estudo apresenta alguns elementos para a construção de um percurso historiográfico do livro didático de português (LDP), cuja elaboração está intimamente associada às políticas públicas para a produção, a aquisição e a distribuição de material didático. Por meio de pesquisa documental e bibliográfica, este artigo aponta e discute elementos que permitem constatar como o governo, desde o Brasil Colônia, exerce um controle sobre a produção e a circulação do material didático para o ensino de língua materna. Os resultados da pesquisa indicam que os manuais didáticos são produzidos conforme definem documentos oficiais que regulam a edição e a circulação do LDP, configurando uma ordem do discurso sobre o livro didático a qual tem cristalizado um modelo de produção do LDP.

Palavras-chave: Livro didático de português; Historiografia-linguística; Ensino de língua materna; Programa Nacional do Livro Didático.

\section{Introdução}

O presente artigo é um recorte da pesquisa "Livro didático de português: um percurso histórico" - desenvolvida na Universidade Estadual de Goiás (UEG), Unidade Universitária de Inhumas - que propõe um estudo historiográfico acerca do livro didático de português (LDP). Infelizmente, não há muitos estudos que tratem especificamente da história do LDP, mas é consenso entre as pesquisas

\footnotetext{
Doutor em Letras e Linguística (2016) pela Universidade Federal e Goiás, é Mestre em Letras e Linguística (2009) pela mesma instituição, onde também cursou a graduação em Letras-Português (2005). É graduado em Filosofia pela Pontifícia Universidade Católica de Goiás (2000). Atualmente, é professor do quadro permanente da Universidade Estadual de Goiás, Unidade Universitária de Inhumas, atuando na área de língua portuguesa e linguística. Também leciona língua portuguesa na educação básica e dedica-se a pesquisas que tomam como corpus o livro didático de português para a abordagem e a discussão dos eventos relacionados à sala de aula de língua materna. Em suas atividades de pesquisa, apoia-se nos pressupostos teórico-metodológicos dos estudos bakhtinianos, da historiografia linguística, da linguística aplicada e dos estudos do texto e do discurso. Interessa-se, igualmente, por pesquisas que discutem a interface filosofia-linguística, notadamente aquelas ligadas à filosofia da linguagem e às teorias do signo. E-mail: wcarvalhaes@hotmail.com
}

Data de submissão: dez. 2020 - Data de aceite: mar. 2021 http://dx.doi.org/10.5335/rdes.v17i01.11402 
da área, como as de Freitag, Motta e Costa (1989) e Oliveira et al. (1984), a hipótese de que a produção didática é muito influenciada por orientações do Governo Federal, principal comprador de livros didáticos no Brasil.

Por meio de pesquisa documental e bibliográfica, investigamos como o governo, desde o Brasil Colônia, exerce um controle sobre a produção e a circulação do material didático para o ensino de língua materna. $\mathrm{O}$ estudo apoia-se nos pressupostos teóricos apontados por Koerner (1996) e Milani (2011) e toma como paradigma de investigação historiográfico-linguística os trabalhos de Milani (2012a, 2012b) e de Rosa (2011). Na primeira parte do artigo, apontamos um breve histórico sobre a edição do livro didático no Brasil, seguindo o percurso indicado por Araújo (1999) e Hallewell (2005), pois o modo como a indústria editorial didática brasileira desenvolveu-se influencia o processo de elaboração, de edição e de circulação do LDP. Na segunda parte, tratamos dos gestos oficiais que explicitam o controle governamental sobre a produção didática e, no terceiro tópico, apontamos os órgãos e programas governamentais que materializam as políticas públicas para a edição de obras didáticas no Brasil. A segunda e a terceira partes do artigo tratam, portanto, da relação entre a produção do material didático e a regulamentação do governo.
Essa relação é importante para a elaboração de um percurso historiográfico-linguístico do LDP, pois, conforme Koerner (1996) e Milani (2001), a historiografia-linguística toma um dado objeto como materialização do pensamento de uma época, constituído no curso de determinadas relações de força. No caso em questão, essas relações dão-se entre governo-editoras-equipe autoral. Os manuais didáticos são produzidos conforme definem documentos oficiais que regulam a edição e a circulação do LDP, configurando uma ordem do discurso sobre o livro didático (LD) a qual tem cristalizado um modelo de produção do LDP, como apresentamos nas considerações finais.

\section{Elementos para a compreensão da produção editorial didática no Brasil}

Para Hallewell (2005), a década de 1850 é um marco divisor na história da publicação de obras didáticas no Brasil. Segundo o autor, foi a partir desse momento que as tipografias que publicavam jornais, muitas vezes respondendo a solicitações de governos municipais, passaram a editar livros a serem usados em escolas. Esses livros didáticos, que circulavam paralelamente aos jornais, por serem editados em razão de uma 
demanda específica, não eram mercadologicamente atrativos. Conforme Hallewell (2005, p. 216), Baptiste Louis Garnier, dono da editora Garnier, foi "o primeiro editor a envidar um verdadeiro esforço para atender às necessidades de livros escolares brasileiros e assumir um comercial por sua própria iniciativa”. Segundo Costa (2011, p. 15, grifo do autor), no caso de livros sobre a história brasileira, embora já houvesse outras obras de cunho histórico, "aquele que foi considerado o primeiro livro didático foi o Lições de História do Brasil para uso dos alunos do Colégio de Pedro II de Joaquim Manoel de Macedo, editado por Garnier a partir de 1861".

Em 1850, momento histórico de raras editoras, destacam-se duas casas editoriais: Garnier e Laemmert. A Garnier conquistou o primeiro espaço na publicação de obras didáticas. A Laemmert destacou-se na publicação de obras literárias e também publicou algumas obras didáticas, como o longevo manual Por que me ufano do meu país, de Afonso Celso, publicado em 1901, leitura obrigatória em escolas secundárias do Brasil durante muitos anos.

Até o fim do século XIX, as atividades editoriais giravam em torno das necessidades das faculdades, ainda em número restrito no país, e de uma elite leitora, com edição de livros de estudo e de literatura. Em 1860, a Garnier abre uma filial, a Casa Garraux, que, além de livros, vendia artigos de papelaria e outros itens, fato que tornou essa livraria um espaço significativo para a vida cultural da elite do Rio de Janeiro de então.

Posterior às editoras Garnier e Laemmert, mas não menos importante, surge, na década de 1880, a editora Francisco Alves. Segundo Hallewell (2008), não obstante o pioneirismo de Baptiste Louis Garnier, Francisco Alves destacou-se entre os editores da segunda metade do século XIX e primeiros anos do século $\mathrm{XX}$ ao fazer da produção didática sua principal linha editorial. A partir da década de 1890, a editora Francisco Alves teve grande atuação na produção do livro didático no Brasil.

Para Costa (2011), é preciso considerar que Francisco Alves foi favorecido por uma conjuntura político-educacional diferente daquela em que se inseriram seus predecessores. $\mathrm{O}$ governo republicano, conforme acentuam Aranha (1996) e Piletti, C. e Piletti, N. (2013), promoveu a educação pública, em detrimento da educação elitista do período imperial. Como reflexo dessa mudança de foco, o número de estudantes aumentou e, consequentemente, mais livros didáticos eram consumidos.

No cenário da edição de material didático, surge, em 1902, a editora FTD, cujo nome é uma homenagem a Frère Theóphane Durand, que, de 1883 a 1907, foi superior-geral do Instituto Marista, congregação religiosa católica cujo caris- 
ma é a educação. Durand, conforme as informações no site da $\mathrm{FTD}^{1}$, foi grande incentivador da produção de obras didáticas. Em 1897, por determinação do superior-geral, são enviados os primeiros Irmãos Maristas ao Brasil que, em sua bagagem, traziam os primeiros livros da FTD, edições francesas que já integravam a rotina dos colégios maristas em vários países. Essas obras francesas foram traduzidas, adaptadas e novos livros foram escritos de acordo com a realidade brasileira, como a obra Exercícios de Cálculo sobre as Quatro Operações, primeiro livro publicado pelos maristas no Brasil, em 1902 (FTD, 2012).

Ainda segundo as informações no site da FTD, a editora, nos primeiros anos do século XX, tornou-se referência em material didático, pois suas obras, editadas conforme o um padrão denominado "Método FTD", passaram a ser adotadas em muitas escolas brasileiras, tanto da rede pública quanto da rede privada. Essa ampla adoção dos livros da editora justifica-se pelo fato de essas obras apresentarem

[...] o Livro do Mestre [que] passou a ser visto como um guia seguro que trazia economia de tempo para os professores e farto material para os alunos trabalharem ${ }^{2}$ (FTD, 2012, s.p.).

$\mathrm{O}$ site da FTD afirma que essa editora, ainda hoje mantida pelos Irmãos Maristas, influenciou a produção didática brasileira, pois, após o ano de 1950, as editoras que se dedicam à publicação de material didático seguem o caminho traçado pela FTD.

Segundo Hallewell (2005), em 1914, é fundada a Livraria Acadêmica, que, mais tarde, torna-se a editora Saraiva. Em 1917, depois da morte de Francisco Alves, sua editora passa a outros proprietários e dá origem à empresa Paulo de Azevedo e Companhia, que continua exibindo a marca Francisco Alves, mas que deixa de ter como foco principal a publicação de obras didáticas.

Nesses primeiros anos do século XX, decisivos para a configuração da imprensa didática e, consequentemente, para a indicação dos rumos do livro didático, não podemos deixar de registrar a importante contribuição de Monteiro Lobato na produção de livros no Brasil. Para publicar suas obras e as de novos autores, funda a Gráfica Monteiro Lobato e Cia. e não mede esforços no sentido de publicar obras que aproximassem as pessoas da leitura. Monteiro Lobato, além de sua produção própria na literatura brasileira, traduziu muitos clássicos da literatura universal a fim de aproximá-los do leitor brasileiro. $\mathrm{O}$ autor-editor fomentou a circulação das obras de sua editora em todos os locais de venda possíveis. Oferecia, em regime de consignação, livros que ficavam expostos até nos armazéns de "secos e molhados" muito comuns no interior dos rincões brasileiros. Se não havia livraria, fazia-se mister que os 
livros fossem oferecidos de algum modo, não raras vezes, entre gêneros alimentícios, cortes de fazendas e toda sorte de produtos expostos nos interioranos comércios. Entretanto, não obstante o hercúleo esforço de Monteiro Lobato, sua gráfica acabou indo à falência.

A gráfica de Lobato, segundo Hallewell (2005), torna-se, em 1915, a editora Companhia Melhoramentos, que, ao contrário da Editora Francisco Alves, tinha como foco principal os livros literários e os livros infantis. Depois da Primeira Guerra Mundial, sentindo os efeitos econômicos do pós-guerra, Lobato resolve também investir nas produções didáticas. Em sociedade com Octalles Marcondes Ferreira, funda a Editora Nacional, em 1925. Em 1932, Ferreira, já sozinho na editora, funde-a com a Civilização Brasileira e utiliza as duas marcas. A partir de 1933, entretanto, a produção didática sai apenas pela Editora Nacional que, ainda hoje, publica materiais didáticos e paradidáticos.

Costa (2011) aponta dois pontos que favoreceram o êxito da inserção da Editora Nacional no cenário de publicação de obras didáticas: a reestruturação pela qual passou a Editora Francisco Alves, após a morte de seu fundador, e a socialização, no Brasil dos anos de 1920, das propostas do movimento conhecido como Escola Nova.

Esse movimento desenvolveu-se sobre o pensamento de John Dewey, filósofo e pedagogo norte-americano. Para Dewey (1959, p. 83), a educação deveria ser compreendida como

[...] reconstrução ou reorganização da experiência, que esclarece e aumenta o sentido desta e também a nossa aptidão para dirigirmos o curso das experiências subsequentes.

Nesse sentido, a educação escolar, para o autor, deveria estar associada à vida dos envolvidos no processo de ensino-aprendizagem. A escola não poderia restringir-se ao repasse de informações, mas deveria orientar-se para o desenvolvimento dos saberes e competências necessários para a vida do cidadão. A escola, para Dewey (1971, p. 7), não seria mais lugar de "preparação para a vida", seria "a própria vida".

No Brasil, as contribuições de Dewey tiveram grande efeito sobre a conjuntura político-educacional que se estabeleceu a partir da década de 1920. O modelo educacional de então, que privilegiava a formação das elites, foi questionado. Para substituí-lo,

[...] propunha-se a instituição de um sistema nacional de educação, [...] com ênfase na educação básica, mas formando um todo articulado, do primário ao superior (PILETTI, C.; PILETTI, N., 2013, p. 166).

Essa proposta começa a efetivar-se com a Revolução de 1930. Se, no final da Primeira República, conforme Piletti, C. e Piletti, N. (2013), a educação continuava seguindo os moldes do final 
do período colonial, com a Revolução de 1930, essa realidade começa a se alterar. Isso se dá porque alguns reformadores educacionais da década anterior passam a ocupar cargos na administração do ensino. A criação do Ministério da Educação e das Secretarias de Educação dos Estados - em substituição às antigas Diretorias-Gerais de Instrução Pública - foi a primeira mudança empreendida pela Revolução de 1930. Para Piletti, C. e Piletti, N. (2013, p. 173-174, grifos dos autores), essa iniciativa

[...] representou uma importante mudança conceitual, qual seja, a substituição de instrução, conceito restrito e limitado à transmissão de conhecimentos e ordens, por educação, [...] compreendendo a formação integral da pessoa.

Está claro, como mostram Piletti, C. e Piletti, N. (2013), que a realidade da educação até a segunda década do século XX ainda mostrava traços da desarticulação característica do período imperial. Não havia um sistema nacional de educação; o ensino primário era responsabilidade dos estados (com reduzidos recursos); o ensino secundário era irregular (concebido apenas como meio de acesso ao ensino superior); o ensino superior reduzia-se a escolas isoladas. Diante dessa desarticulação, a criação do Ministério da Educação e das Secretarias de Educação dos Estados representa, como acentuam Piletti, C. e Piletti, N. (2013), uma sistematização da educação no Brasil. Em nossa análise, se, por um lado, houve essa mudança conceitual, por outro, houve um processo de centralização da gestão da educação que, posteriormente, no Estado Novo (1937-1945), é potencializada.

Para Hallewell (2005), esse cenário de transformação favoreceu a Editora Nacional, pois os investimentos na organização da educação pública fizeram crescer o número de alunos nas escolas e, consequentemente, estimularam a produção de mais livros didáticos. Hallewell (2005) acrescenta que a Revolução de 1930 e o movimento Escola Nova fizeram surgir outra casa editorial no mercado de livros didáticos: a Editora Globo, de Porto Alegre.

De modo geral, no fim do século XIX e nos primeiros anos do século XX, embora tenham ocorrido várias mudanças na educação brasileira, nossa pesquisa, até o momento, observa que os materiais didáticos de língua portuguesa pouco se alteraram. Os LDP desse período aos quais tivemos acesso são ainda elaborados no caminho das antologias de texto que foram objeto de estudo de Razzini (1992, 2000, 2002).

Neste tópico, discutimos aspectos históricos sobre a produção editorial no Brasil, aos quais se associam a produção de obras didáticas e, por extensão, a produção de obras didáticas para o ensino de língua portuguesa. Para a constituição de um percurso historiográfico do $\mathrm{LD}$ e, 
por extensão, do LDP, a esses apontamentos históricos, somam-se a discussão acerca do controle e da regulamentação do governo sobre a produção de obras didáticas, ponto do qual passamos a tratar.

\section{A produção de material didático e a regulamentação do governo}

Witzel (2002), em seu estudo sobre o LDP e a identidade do professor de língua portuguesa, afirma que só é possível discorrer sobre a história do livro didático se o fizermos com base na consideração da política do livro didático como apontado em Freitag, Motta e Costa (1989) e Oliveira et al. (1984). Para o percurso historiográfico-linguístico que aqui propomos, observar a relação entre a produção didática e o controle do governo é fundamental, pois, na relação entre a regulamentação do governo e a produção da obra didática, desenha-se um percurso significativo para uma abordagem analítica que toma o LDP como monumento.A noção de monumento é apresentada por Foucault (2010) e por Le Goff (1996). Para Foucault (2010), a história tradicional metódica toma os acontecimentos, os episódios da vida social - que ele chama de monumentos - e transforma-os em documentos, em registros oficiais. Nas palavras do autor:
Digamos, para resumir, que a história, em sua forma tradicional empreendia "memorizar" os monumentos do passado, transformá-los em documentos e fazer falar estes rastros que, por si mesmos, raramente são verbais, ou que dizem em silêncio coisa diversa do que dizem; em nossos dias, a história é o que transforma os documentos em monumentos, e desdobra, onde se decifravam traços deixados pelos homens, onde se tentava reconhecer em profundidade o que tinham sido, desdobra uma massa de elementos que devem ser isolados, agrupados, tornados pertinentes, inter-relacionados, organizados em conjuntos (FOUCAULT, 2010 , p. 8, grifos do autor).

Para Foucault (2010, p. 8), o trabalho com o monumento é uma atividade arqueológica, que se "volta à descrição intrínseca do monumento". No caso do LDP, objeto do presente estudo, trata-se de perguntar: Por que o LDP se constitui como elemento importante na prática de ensino? Por que o governo controla o LDP? Por que o governo compra o LDP para as escolas públicas? Tratar o LDP como monumento é fugir das intepretações simplistas e reducionistas de uma realidade complexa; é pensar nas lutas pela imposição de saberes (FOUCAULT, 2010); é operar sobre o LDP, um documento, ordenando-o a partir de seu interior em relação ao contexto que lhe dá possibilidade de existência, construindo unidades que o tornam monumento, descrevendo, enfim, os discursos que nele materializam-se.

Na esteira de Foucault (2010), Le Goff (1996, p. 535), postula que a história, 
forma científica da memória coletiva, constrói-se por materiais da memória, que "podem apresentar-se sob duas formas principais: os monumentos, herança do passado, e os documentos, escolha do historiador". Discutindo sobre essas noções, Le Goff (1996, p. 536) afirma que, inicialmente, o monumento é visto como um material de valor questionável, caracterizado "pelo poder de perpetuação, voluntária ou involuntária, das sociedades históricas", por meio de expressões não escritas. O documento, ao contrário, expressão essencialmente escrita, é considerado mais legítimo por ser associado à "neutralidade". Le Goff (1996) desconstrói a dicotomia entre documento e monumento, afirmando que todo documento é, também, parcial, pois é fruto das escolhas de quem o elabora. $\mathrm{O}$ que existe, desse modo, é um modo específico de abordagem que pode considerar o dado como documento ou monumento. Assim, para Le Goff (1996, p. 545), “o documento não é qualquer coisa que fica por conta do passado, é um produto da sociedade que o fabricou segundo as relações de forças que aí detinham o poder. Só a análise do documento enquanto monumento permite à memória coletiva recuperá-lo [...]”. A construção da memória coletiva, portanto, passa por uma opção epistêmico-metodológica que toma um dado histórico como documento-monumento. Foucault (2010) e Le Goff (1996) ressaltam a necessidade metodológica de que a abordagem historiográfica considere o documento como monumento.

Neste artigo, em que propomos um percurso historiográfico-linguístico do LDP, fundamentamo-nos na metodologia da Historiografia Linguística. Um estudo historiográfico-linguístico toma seu objeto "como monumento, ou seja, [como elemento] reconhecido por representar um pensamento dentro de uma sociedade", devendo ser compreendido "como refração das fontes formadoras, da prática cultural e da ordem de coisas presentes no contexto do texto-discurso" (MILANI, 2011, p. 10).

Nesse sentido, o LDP, entendido a partir da noção de monumento, oferece-nos suporte para entender como o controle do governo sobre a produção didática - iniciado, segundo Almeida (2008), com a expulsão dos jesuítas - influencia a produção e a reprodução de determinado modelo de material didático.

O governo brasileiro, especialmente a partir de 1937, como apontam os trabalhos de Freitag, Motta e Costa (1989), Lemos (2010) e Witzel (2002), configura-se como o maior comprador de livros didáticos. Nessa perspectiva, o controle governamental sobre a produção de materiais didáticos, exercido pelo governo federal, torna-se um meio pelo qual se pode compreender o estado atual da produção do LDP. 
Almeida (2008), em seu estudo sobre como se organizavam as aulas régias no Brasil colonial, afirma que a expulsão dos jesuítas fez-se acompanhar do primeiro gesto oficial de controle da produção de material didático por parte do governo em terras brasileiras. Isso se deu, pois era preciso garantir, por meio do material usado pelos estudantes, que as ideias jesuíticas fossem substituídas pela ideologia pombalina.

Outro gesto oficial do governo para o estabelecimento de um controle da produção de obras didáticas foi a Lei de 17 de fevereiro de 1854. Essa lei, elaborada na gestão do ministro Luiz Pereira de Coutto Ferraz, regulamentou a instrução primária e secundária, suprimiu as aulas régias e criou a Inspetoria Geral da Instrução Primária e Secundária da Corte $^{3}$. Segundo Gondra (2005, p. 19),

[...] o aparelho gerado nos termos dessa intervenção supõe uma profissionalização da instrução, impondo regras para ingresso e permanência de alunos e professores, redefinindo os saberes escolares, ao mesmo tempo em que instaura uma rede de vigilância sobre a organização escolar e seus sujeitos por intermédio da qual se pretendia obter eficiência e eficácia na instrução primária e secundária da Corte.

A "profissionalização da instrução" foi uma ação do governo imperial no intuito de gerir a educação brasileira que, nesse momento, apresentara-se de forma desarticulada. Essa gestão amplia-se na imposição de regras, controle do tempo e na definição do que a escola deve ensinar.
Objetivando "eficiência" e "eficácia", a Lei de 1854 estabelece vigilância à organização e ao funcionamento da escola. Entre outras atribuições da inspetoria criada pela Lei de 1854, inclui-se a de revisar os compêndios (a expressão "livro didático" só é oficialmente empregada em 1937), utilizados nas escolas públicas, corrigi-los e, quando necessário, substituí-los. Também era função da inspetoria a convocação do Conselho Diretor que definia métodos e sistemas de ensino e designava os compêndios a serem usados nas escolas. Embora o Conselho Diretor da Inspetoria Geral de Instrução Primária e Secundária da Corte fosse responsável pela indicação dos manuais, contava com o auxílio de pessoas externas à inspetoria, já que as obras a serem escolhidas

[...] eram encaminhadas pelo Conselho a pessoas consideradas "idôneas" da época e que fossem de confiança das autoridades, sendo uma significativa parcela desses sujeitos formados por professores públicos, para que estas pudessem fazer sua avaliação, aprovando somente obras que estivessem de acordo com os interesses do poder vigente. Ao mesmo tempo em que previa a regulação, o governo incentivava a criação destas obras ao garantir, nos artigos $56^{\circ}$ e $95^{\circ}$ do regulamento, prêmios às pessoas que compusessem compêndios para uso das escolas e aos que melhor traduzissem os publicados em língua estrangeira (LEMOS, 2010, p. 19).

Percebe-se, nesse excerto, como o controle sobre o material didático é intensificado a partir de 1854. Desde 
esse momento histórico, já se estabelece uma prática hoje comum em relação à escolha de material didático: a consulta externa. Em 1854, a consulta era feita a pessoas "idôneas", certamente intelectuais ou pessoas ligadas ao governo, e a professores. Embora houvesse a consulta, fica claro que, no fim das contas, eram escolhidos apenas os manuais que estivessem alinhados ao que pensava $o$ governo, o que já configura uma forma de controle. Os estudos de Almeida (2008) apontam que essa situação se mantém durante toda a segunda metade do século XIX, inclusive após a proclamação da república. A realidade educacional brasileira, entre 1889 e 1930, conforme destacam Piletti, C. e Piletti, N. (2013), conserva os traços básicos do fim do império. $\mathrm{O}$ ensino mantém-se em um pequeno número de escolas públicas e são poucos os estabelecimentos com cursos regulares. A educação primária é tarefa dos estados, que contam com poucos recursos, e o ensino secundário estabelece-se em função do acesso às poucas escolas de ensino superior. Nesse contexto, os programas e as orientações didáticas referem-se ao que era proposto no Colégio Pedro II que, mesmo depois do império, continua como referência no ensino secundário oficial.

Para Piletti, C. e Piletti, N. (2013), em concordância com Aranha (1996) e Hilsdorf (2003), a mudança no cenário da educação brasileira ganha contornos com a Revolução de 1930, quando são criadas as secretarias estaduais de educação, em substituição às Diretorias-Gerais da Instrução Pública, órgãos estatais que, até então, eram responsáveis por gerir a educação nos estados brasileiros.

Conforme Piletti, C. e Piletti, N. (2013), após a Revolução de 1930, intelectuais que pensavam a educação de um modo menos elitista e mais popular começaram a ocupar cargos no governo. Essa realidade favorece a mudança de foco do ensino público brasileiro, que se abre para as contribuições da escola nova, ou educação nova, de John Dewey (1959). Esse processo de mudança, entretanto, estanca quando Gustavo Capanema, ministro da educação do governo constitucional (1934-1937) e do Estado Novo (1937-1945), promove

[...] a reforma de todos os graus e modalidades de ensino, em iniciativas impostadas de cima para baixo, por meio de decretos-lei, já que o Congresso fora fechado pelo ditador [Getúlio Vargas] (PILETTI, C.; PILETTI, N., 2013, p. 182).

Em um cenário histórico marcado por um retorno aos padrões de uma educação elitista, a centralização da gestão, como é próprio de um governo autoritário, atinge também a área educacional. Gustavo Capanema estabeleceu uma legislação de tal modo centralizadora que se criou a ideia geral de que "a qualquer hora do dia, o ministro, em seu gabinete no Rio de Janeiro, sabia o que estava ocorrendo 
na sala de aula de todas as escolas do país" (PILETTI, C.; PILETTI, N. 2013, p. 185). Chama a atenção o fato de essa legislação centralizadora ter prevalecido até 1961, dezesseis anos depois da queda do Estado Novo, quando foi aprovada a primeira Lei de Diretrizes e Bases da Educação Nacional.

Como já vimos anteriormente, consoante Almeida (2008), o controle sobre a produção do material didático estabeleceu-se com a expulsão dos religiosos jesuítas, em 1759, e intensificou-se, em 1854, com a fundação da Inspetoria Geral da Instrução Primária e Secundária da Corte.

A centralização na gestão da educação, resultado da atuação de Gustavo Capanema à frente do Ministério da Educação durante o governo constitucional (1934-1937) e o governo do Estado Novo (1937-1945), amplia a sistematização de mecanismos de controle especificamente voltados para a elaboração, a publicação e a circulação do livro didático. Isso se dá pela instituição de órgãos e de programas governamentais com a tarefa específica de regulamentar a produção e a publicação dos livros didáticos. No próximo tópico, propomos um inventário desses gestos oficiais.

\section{Órgãos e programas governamentais de controle do livro didático}

No caso do material didático, a sistematização e a centralização do controle gestor por parte do governo tornam-se mais efetivas com a fundação do Instituto Nacional do Livro Didático (INL), em $1937^{4}$, quando Gustavo Capanema inicia seu segundo mandato como ministro da educação.

Segundo Witzel (2002), a fundação do INL, precursor do atual Programa Nacional do Livro Didático (PNLD), causa mudanças significativas no percurso referente à edição e à circulação de livros didáticos. O INL, criado por meio do Decreto-Lei no $^{\circ}$ 93, de 21 de dezembro de 1937, tinha como atribuições iniciais: a edição de obras literárias consideradas importantes para a formação cultural dos brasileiros, a organização de uma enciclopédia e de um dicionário nacionais e a criação de bibliotecas públicas.

No ano seguinte, pelo Decreto-Lei $\mathrm{n}^{\mathrm{o}}$ 1.006, de 30 de dezembro de 1938, foi criada a Comissão Nacional do Livro Didático (CNLD). Essa comissão, formada por membros nomeados pelo Presidente da República (Getúlio Vargas), estabelece a primeira legislação para a produção e a circulação de obras didáticas. Embora, segundo o Decreto-Lei $\mathrm{n}^{\mathrm{0}} 1.006$, a criação da comissão tivesse o objetivo de 
evitar impropriedades factuais e inexatidões nas obras didáticas, Freitag et al. (1989) e Hallewell (2005) afirmam que essa comissão surgiu com uma clara função de controle político-ideológico e não com um objetivo didático como apontado pelo decreto.

Segundo Witzel (2002), até 1937/1938, não havia uma definição precisa do que era livro didático. Foi justamente em 1938, que se consagrou "o termo 'livro-didático' entendido até os dias de hoje como sendo, basicamente, o livro adotado na escola, destinado ao ensino, cuja proposta deve obedecer aos programas curriculares escolares" (WITZEL, 2002, p. 17). Assim se definiu livro didático no Decreto-Lei nํ 1.006 de 30 de dezembro de 1938, em seu artigo segundo:

Compêndios são os livros que expõem total ou parcialmente a matéria das disciplinas constantes dos programas escolares; livros de leitura de classe são os livros usados para leitura dos alunos em aula; tais livros também são chamados de livro-texto, compêndio escolar, livro escolar, livro de classe, manual, livro didático (OLIVEIRA, 1980, p.12 apud OLIVEIRA et al, 1984, p. 22).

\section{Essa definição}

[...] privilegia o aspecto da 'consagração' ou legitimação do livro no próprio processo de ensino; o livro didático é basicamente o livro adotado na escola (OLIVEIRA et al., 1984, p. 23).

No escopo de nosso trabalho, essa definição fixa-se como um enunciado importante, pois entendemos que a definição de 1938 ainda reverbera na configuração dos LD atuais, e, por extensão, dos LDP.

Além de apresentar a definição de livro didático, o decreto-lei criou a CNLD a cujos membros, indicados pelo governo, cabia, entre outras, as funções de examinar, avaliar e julgar os livros didáticos, autorizando ou não seu uso nas escolas. Percebe-se, pois, aqui, uma verticalização do controle iniciado com expulsão dos jesuítas, em 1759, e intensificado, em 1854, com a fundação da Inspetoria Geral da Instrução Primária e Secundária da Corte.

A atitude governamental de criar a CNLD, em pleno período do Estado Novo, um momento político autoritário, marcante e polêmico, como pontuam Freitag, Motta e Costa (1989), foi uma iniciativa que buscava garantir a unidade/identidade nacional. Por um lado, essa unidade revela-se na centralização da gestão da produção e da circulação do LD. Por outro, o próprio LD, ao submeter-se aos critérios da CNLD, constitui-se como um veículo de legitimação dessa unidade/identidade nacional objetivada pelo governo de Getúlio Vargas.

O poder da CNLD foi questionado, especialmente em razão de os critérios da comissão, segundo observação de Oliveira et al. (1984), valorizarem mais aspectos político-ideológicos do que pedagógicos, já que o que estava em pauta era assegurar que os LD atendessem 
aos propósitos de formação de um certo espírito de nacionalidade. Oliveira et al. (1984) explicam que, dos critérios de impedimentos para adoção de uma obra didática estabelecidos pela comissão, apenas cinco tratavam de aspectos didáticos propriamente ditos, enquanto onze estavam associados a questões político-ideológicas como aspectos morais, cívicos e políticos. Com a CNDL, percebem-se mudanças nas políticas do LD. Todavia, entre a comissão e o atual (PNLD) há um traço comum: o controle governamental (ou sua tentativa), às vezes explícito no discurso governamental, às vezes subjacente ao que se enuncia nos documentos oficiais.

A existência da CNLD não foi tranquila em função de constituir-se como um processo permeado por impasses e dificuldades próprias da

[...] centralização do poder, do risco da censura, das acusações de especulação comercial e de manipulação política, relacionada com o livro didático (FREITAG; MOTTA; COSTA, 1989, p. 14).

Não obstante as dificuldades de operacionalização da comissão e as loquazes críticas dos intelectuais da época a essa forma de centralização, o órgão manteve-se e foi ampliado. A CNLD funciona até 1945. Nesse ano, após a queda do governo de Vargas, o Estado restringe ao professor a escolha do material didático a ser usado pelos alunos e, por meio do Decreto-Lei no ${ }^{\circ}$.460, de 26 de dezembro de 1945, dissolve a CNLD. O INL é extinto apenas em 1976.

No caminho do controle governamental da produção didática, até o atual PNLD, há a criação e a extinção de vários órgãos e programas. Conforme Freitag, Motta e Costa (1989), após a dissolução da CNLD, criam-se outros órgãos, comissões e programas que antecedem o atual PNLD ou que a ele de algum modo estão relacionados:

- Fundação Nacional do Material Escolar (FENAME), de 1967 a 1983;

- Comissão do Livro Técnico e do Livro Didático (COLTED), de 1967 a 1971;

- Fundo Nacional de Desenvolvimento da Educação (FNDE), de 1968 à atualidade,

- Programa do Livro Didático (PLID) $)^{5}$, de 1971 a 1985;

- Fundação de Assistência ao Estudante (FAE), de 1983 a 1997;

- Programa Nacional do Livro Didático (PNLD), de 1985 à atualidade.

Em nossa pesquisa, ao procurarmos informações sobre esses organismos de gestão sobre a produção e a circulação do LD, percorremos um intricado caminho no qual se entrecruzam datas, justificativas pedagógicas, objetivos político-ideológicos, questões didáticas e logísticas de naturezas diversas. O modo como decidimos organizar esse complexo emaranhado de informações segue o percurso cronológico da criação 
dos vários órgãos, comissões e programas de algum modo associados à política do governo sobre o LD.

A Fundação Nacional do Material Escolar (FENAME) foi criada por meio da Lei oㅜ 5. 327, de 02 de outubro de 1967, durante o governo de Arthur Costa e Silva. A FENAME, conforme pontua Höfling (2000, p. 163), tinha como finalidade primeira a produção e a distribuição de materiais didáticos às escolas, "mas não contava com organização administrativa nem recursos financeiros para desempenhar tal tarefa". Em virtude dessa situação, estabeleceu-se, por meio da Portaria Ministerial nº 35, de 1970, um sistema de coedição com as editoras nacionais. Nesse sistema, a FENAME tinha a tarefa de definir os critérios para a elaboração do material didático e de revisá-lo quando necessário. A atuação da FENAME torna-se mais efetiva em 1976. Com o Decreto ${ }^{\circ} 77.107$, de 04 de fevereiro de 1976, o então presidente Ernesto Geisel transfere à FENAME a responsabilidade do PLID, até então competência do INL.

Acerca das competências da FENAME, Freitag, Motta e Costa (1989, p. 15) explicam que ela deveria definir, a partir de então,

[...] as diretrizes para a produção de material escolar e didático e assegurar sua distribuição em todo território nacional; formular programa editorial; cooperar com instituições educacionais, científicas e culturais, públicas e privadas, na execução de objetivos comuns.
Nessa época, surge, de maneira explícita, a vinculação da política governamental do LD ao caráter assistencialista que vai marcar, por exemplo, a decisão de se transferir para a Fundação de Assistência o Estudante (FAE), no início da década de 80 , o gerenciamento de programas como o Programa do Livro Didático para o Ensino Fundamental (PLIDEF). Essa concepção assistencialista resultou, segundo Freitag, Motta e Costa (1989), em problemas como dificuldades de distribuição dos LD nos prazos previstos; aproximação das empresas e editoras de órgãos governamentais responsáveis a fim de terem escolhidos pelo programa seus LD; além de uma tomada de decisões centralizadora e autoritária por parte dos responsáveis no governo.

Conforme Freitag, Motta e Costa (1989) e Höfling (2000), em 1967, cria-se a Comissão do Livro Técnico e do Livro Didático (COLTED), extinta em 1971. Sob a égide do regime militar, durante os anos 60, a COLTED resultou do Acordo MEC/USAID ${ }^{6}$. Segundo Freitag, Motta e Costa (1989), esse acordo, firmado em 06 de janeiro de 1967, objetivava disponibilizar gratuitamente, no período de três anos, cerca de 51 milhões de livros para estudantes brasileiros. Ainda conforme os autores, a COLTED propunha um programa desenvolvimentista - para cuja concretização dispunha de farta disponibilidade financeira - que incluiria a instalação de bibliotecas e a organização 
de cursos de treinamentos de instrutores e professores. Entretanto, estudos como o de Höfling (2000) denunciam que, por trás do acordo entre MEC/USAID, havia um interesse norte-americano de controlar as escolas do Brasil. Esse controle, para Freitag, Motta e Costa (1989), revela-se na elaboração dos LD que, por meio de uma fiscalização de conteúdo, naquele contexto, tornam-se instrumentos ideológicos dessa manipulação. Os resultados do trabalho da COLTED foram desastrosos e culminaram em uma Comissão de Inquérito para apuração de possíveis irregularidades e corrupção no mercado livreiro, notadamente em relação à edição, divulgação e comercialização do LD.

O Fundo Nacional de Desenvolvimento da Educação (FNDE) foi criado pela Lei $\mathrm{n}^{\mathrm{o}} 5.537$, de 21 de novembro de 1968, no governo Arthur da Costa e Silva. Em funcionamento até a atualidade, esse fundo, uma autarquia vinculada ao Ministério da Educação, tem como principal responsabilidade a captação e a distribuição de recursos, via governo federal, para as instituições de educação básica do Brasil. Vários programas relacionados à educação, como o atual PNLD, estão vinculados ao FNDE.

Em 1971, depois da extinção da COLTED, a responsabilidade pela coedição de obras didáticas, em conjunto com as editoras, passa ao INL. Cria-se, então, o Programa do Livro Didático (PLID). Esse programa assume a função de ope- racionalizar a edição e a distribuição de obras didáticas. Tendo terminado o convênio MEC/USAID, os estados passam a contribuir financeiramente para que os LD possam ser editados e enviados às escolas do Brasil. O INL, conforme Höfling (2000), até 1975, promove, em conjunto com as editoras, um acordo de coedição de obras didáticas. Nesse contexto, o Estado passa de "censor" do LD a "financiador" desse material. O PLID foi assumido, em 1976, por determinação de decreto presidencial, pela FENAME, criada em 1968.

Em 1983, organiza-se a Fundação Nacional do Estudante (FAE), em substituição à FENAME. AFAE, criada pela Lei ${ }^{0}$ 7.091, de 18 de abril de 1983, como nova denominação da FENAME, assume como tarefa principal a diminuição nos custos de produção do material escolar (não só do LD), fazendo que chegue a um maior número de alunos. Em 1984, ressalta Höfling (2000), o sistema de coedição é finalizado. Desse modo, o governo passa de "financiador" a "comprador" do LD. E não se trata de um comprador comum, pois há a intenção de que todos os alunos matriculados nas escolas públicas tenham $\mathrm{LD}$ em mãos. Na busca de concretizar esse objetivo, conforme Cury (2009, p. 225),

[...] ao mesmo tempo em que deu continuidade às ações de assistência ao estudante, desenvolvidas anteriormente [...], a FAE foi gradativamente instituindo normas reguladoras dessas ações e organizando-as em programas, além de implementar novas ações. 
Entre essas novas ações, figura a criação do atual Programa Nacional do Livro Didático (PNLD). A FAE é extinta em 1997, quando o PNLD passa a ser desenvolvido pelo FNDE.

Em 19 de agosto de 1985, por meio do Decreto ${ }^{\circ} 91.542$, o presidente José Sarney institui o Programa Nacional do Livro Didático (PNLD). Conforme Cury (2009, p. 126), a criação desse programa ocorreu "no contexto da definição de políticas de assistência ao estudante, unificadas na recém-criada Fundação de Assistência ao Estudante. A FAE procurou consolidar essas políticas em programas próprios segundo as diferentes áreas de atuação". O PNLD, nessa perspectiva, surge como um meio assistencial pelo qual o LD pode chegar ao maior número de estudantes das escolas públicas brasileiras.

\section{Considerações finais}

O PNLD é considerado o maior programa do mundo para a aquisição e distribuição gratuita de material escolar e sua longevidade atesta a importância desse programa para as escolas públicas brasileiras. Mas, um simples olhar sobre o edital e o guia de uma edição do PNLD (BRASIL, 2014, 2018) revelam como esse programa, face atual de um controle iniciado há muito tempo, condiciona a elaboração do LDP, criando padrões segundo os quais um determinado livro pode ou não ser adquirido pelo governo federal.

Entendemos que a criação do PNLD e sua execução são mais um aspecto do controle exercido pelo governo, que pode ser percebido de forma muito marcada em quatro momentos: em 1759, ainda nos tempos do Brasil-Colônia, com a expulsão dos jesuítas; em 1854, no Império, com a fundação da Inspetoria Geral da Instrução Primária e Secundária da Corte; em 1937, no Estado Novo, com fundação do INL e em 1985, com a criação do PNLD. O controle do governo sobre o material didático, como se vê, não é algo novo. E esse controle funciona. Prova disso é o fato de o PNLD estar em pleno desenvolvimento.

A constituição do livro didático está, portanto, condicionada à gestão do governo e essa gestão existe, como provamos, desde 1759. No caso do LD atual, o PNLD, subordinado ao FNDE, orienta programas, normas de produção, inscrição das obras e sua distribuição, o que é feito pelas editoras. Assim, podemos dizer que o PNLD se constitui como um elemento decisivo na elaboração de novos livros didáticos, pondo em relevo o controle que o governo exerce sobre a produção didática. Neste artigo, não nos cabe dizer se esse controle é positivo ou negativo, mas que existe e que precisa ser levado em consideração quando se quer fazer um estudo historiográfico sobre o LDP. 
O autor de um LD vai escrever algo que tenha perspectiva de venda, algo que seja bem avaliado e figure no guia do PNLD, principal consumidor de obras didáticas. Embora a educação privada não dependa do PNLD para a adoção dos livros didáticos, o programa exerce sua influência também nesse âmbito, na medida em que funciona como uma bússola a apontar para o norte do sucesso editorial: as vendas.

Nesse sentido, é muito importante, tomando o LDP como fruto de um momento histórico, compreender que esse objeto é um produto constituído no e pelo discurso, noção que, como aponta Orlandi (1999, p. 15), "tem em si a ideia de curso, de percurso, de correr por, de movimento. $\mathrm{O}$ discurso é assim a palavra em movimento, prática de linguagem: com o estudo do discurso observa-se o homem falando". É nesse movimento, nessa atividade social que marca as situações concretas da existência, que se situam e se configuram nossas práticas sociais, como a produção e a circulação do LDP, por exemplo.

As políticas públicas para o livro didático, em nossa perspectiva, configuram-se como uma forma de controle governamental sobre o material didático. A atuação do governo em relação à produção e à circulação de obras didáticas põe em relevo um conjunto de relações, nas quais se envolvem os órgãos do governo, as editoras, a equipe autoral de livros didáticos e os destinatários desses manuais - professores e alunos. Nesse sentido, é que tomamos o livro didático, entendendo que o LDP se inscreve na ordem do discurso oficial sobre a produção de material didático.

Esse discurso oficial configura uma ordem discursiva que tem cristalizado um modelo de produção do LDP, como mostramos em outra pesquisa que desenvolvemos (CARVALHAES, 2018). A investigação da história do LDP pode nos ajudar a compreender como esse objeto, visto como monumento, materializa nossa forma de ver o mundo, a educação, a língua e seu ensino.

Desejamos que a presente pesquisa colabore no preenchimento de uma lacuna relacionada à escassez de trabalhos científicos que tratam da história do LDP, cuja utilização não é algo novo na atividade pedagógica dos professores do materno idioma. Soares (2001), por exemplo, evidencia essa afirmação ao construir uma história da leitura e da formação do professor-leitor por meio da análise de dois livros didáticos - no caso, A Antologia Nacional, de Fausto Barreto e Carlos de Laet, cuja primeira edição data de 1895, e Estudo dirigido de Português, de Reinaldo Mathias Ferreira, publicado em 1970.

Estudos como os de Soares (2001) e os empreendidos pelos pesquisadores do Centro de Memória da Educação da Faculdade de Educação da Universi- 
dade de São Paulo (USP), por meio da Biblioteca do Livro Didático e do banco de dados virtual dos livros escolares LIVRES, põem em relevo a necessidade de estudos sobre a história do material didático como elemento de compreensão das práticas pedagógicas no ensino de língua portuguesa. Cientes dessa importância, esperamos que nossa pesquisa possa fornecer subsídios para estudos que tomem o material didático como fonte de investigação bem como para estudos sobre o ensino-aprendizagem de língua portuguesa.

\section{Historiographic notes on Portuguese textbooks: government control on the spotlight}

\section{Abstract}

This study presents some elements concerning the construction of a historiographic path of the Portuguese textbook (PT) whose elaboration is closely associated to public politics for its production, purchasing and distribution. After conducting a documentary and bibliographic research, this article indicates and outlines the elements that show how the government, since colonial times in Brazil, have imposed control on the production and circulation of textbooks for teaching Portuguese as a mother tongue. The results point out textbooks are produced according to official documents that set the edition and circulation of PT. That configures as an order of speech over the text- book which has established a formatted pattern for producing it.

Keywords:Portuguese textbooks; Linguistic historiography; Teaching mother tongue; Textbook National Program.

\section{Notas}

1 História da editora FTD. Disponível em: $<$ http://www.ftd.com.br/a-ftd/a-historia $>$. Acesso em 13 mai. 2017.

2 Essa informação é importante, pois já fizemos estudos investigando justamente a relação entre o que se propõe no manual do professor (que o site da FTD denomina "livro do mestre) e o que de fato é apresentado no livro didático.

3 Conforme Piletti e Piletti (2013), entre as décadas de 1840 e 1860, foram criadas Diretorias-Gerais de Instrução Pública em todos os estados do Brasil. Na corte, ou seja, na cidade do Rio de Janeiro, a diretoria recebeu a designação de inspetoria.

4 A página eletrônica do FNDE apresenta como data de fundação para o INL o ano de 1929 . Em Freitag et. al. (1989), bem como em Witzel (2002), aponta-se o ano de 1937. Essa data é corroborada pelo fac simile da lei de criação do INL, que se encontra na página eletrônica do Senado Federal. Disponível em < http:// legis.senado.gov.br/legislacao/ListaNormas. action?numero $=93 \&$ tipo_norma $=$ DEL\&data $=$ $19371221 \&$ link=s>. Acesso em: 13 maio 2020.

5 No histórico do PNLD disponível na página eletrônica do FNDE, assim como em Feijó, Amorim e Rodrigues (2012), esse mesmo programa é denominado Programa do Livro Didático para o Ensino Fundamental (PLIDEF). Em nosso trabalho, optamos por manter a denominação apresentada por Freitag, Motta e Costa (1989). Höfling (2000) explica que o PLID engloba outros programas como o Programa do Livro Didático para o Ensino Fundamental (PLIDEF), o Programa do Livro Didático para o Ensino Médio (PLIDEM), o Programa do Livro Didático para o Ensino Superior (PLIDES) e o Programa do Livro Didático para o Ensino Supletivo (PLIDESU). Esses programas, entretanto, tiveram pequena duração.

6 MEC/USAID: acordo que incluiu convênios realizados entre o Ministério da Educação (MEC) e 
a United States Agency for International Development (USAID), a partir de 1964. Esses convênios objetivavam a implantação do modelo educacional americano no Brasil. O movimento estudantil da época, discordando do acordo, protestou contra os convênios e reivindicou o fim do acordo. Diante disso, as organizações estudantis foram consideradas clandestinas pelo regime militar (DICIONÁRIO INTERATIVO DA EDUCAÇÃO BRASILEIRA, 2008).

\section{Referências}

ALMEIDA, Anita. Aulas régias no império colonial português: o global e o local. In: LIMA, Ivana Stolze; CARMO, Laura do. (Orgs.). História social da língua nacional. Rio de Janeiro: Edições Casa de Rui Barbosa, 2008. p. 65-90.

ARANHA, Maria Lúcia de Arruda. História da Educação. 2. ed. São Paulo: Moderna, 1996.

ARAÚJO, Jorge de Souza. Perfil do leitor colonial. Salvador: UFBA, Ilhéus: UESC, 1999.

BRASIL. Ministério da Educação; Secretaria de Educação Básica. Guia de livros didáticos - PNLD 2018 - Anos finais do Ensino Fundamental. Brasília: MEC, 2007. Disponível em: <http://www.fnde.gov. br/programas/livro-didatico/guia-do-livro/ item/2347-guia-pnld-2018 \%E2\%80\%93-anos-finais-do-ensino-fundamental>. Acesso em: 24 abr. 2020.

- Ministério da Educação; Secretaria de Educação Básica. Edital de convocação para o processo de inscrição e avaliação de coleções didáticas para o Programa Nacional do Livro Didático-2014. Brasília: MEC, 2013. Disponível em: http://www.fnde.gov. br/programas/livro-didatico/livro-didatico-editais. Acesso em: 24 abr. 2020.

CARVALHAES, Wesley Luis. O manual do professor de um livro didático de português: uma abordagem discursiva. Revista Odisseia, Natal, v. 3, n. 1, p. 132-150, maio, 2018.
DICIONÁRIO INTERATIVO DA EDUCAÇÃO BRASILEIRA (DIEB). Disponível em: $<$ http://www.educabrasil.com.br $>$. Acesso em: 04 mar. 2018.

COSTA, Eliezer Raimundo de Souza. O livro didático, um facilitador de informação na escola. Revista Interlocução. Belo Horizonte, p. 13-27, n. 4, v. 4, p. 13-27, jun. 2011.

CURY, Carlos Roberto Jamil. O livro didático como assistência ao estudante. Revista Diálogo Educacional. Curitiba, v. 9, n. 26, p. 119-130, jan./abr. 2009.

FEIJÓ, José Anderson; AMORIM, Francianne Medeiros; RODRIGUES, Yara Katia Santos. Políticas públicas de provisão para os livros didáticos no Brasil: histórico e estudo de caso. Atos de Pesquisa em Educação - Revista do Programa de Pós-Graduação em Educação da Universidade Regional de Blumenau, Blumenau, v. 7, n. 1, p. 69-79, jan./abr., 2012.

FOUCAULT, Michel. A arqueologia do saber. Trad. Luiz Felipe Baeta Neves. 7. ed. Rio de Janeiro: Forense Universitária, 2010.

FREITAG, Bárbara; MOTTA, Valéria Rodrigues; COSTA, Wanderley Ferreira da. O livro didático em questão. Col. Educação Contemporânea. São Paulo: Cortez, 1989.

FTD. História da Editora FTD. [s.l.]: [s.n.], 2012. Disponível em: <http://www.ftd.com. br/a-ftd/a-historia $>$. Acesso em: 13 maio 2018.

GONDRA, José Gonçalves. Ao Correr da Pena: reflexões relativas às cartas de professores do século XIX. In: MIGNOT, Ana Crystina Venâncio; CUNHA, Maria Teresa Santos. (Orgs.). Práticas de memória docente. Rio de Janeiro: Cortez, 2003. p. 17-33.

HALLEWELL, Laurence. O livro no Brasil: sua história. 2. ed. São Paulo: Edusp, 2005.

HILSDORF, Maria Lúcia Spedo. História da educação brasileira: leituras. São Paulo: Pioneira Thomson Learning, 2003. 
HÖFLING, Elloisa de Mattos. Notas para discussão quanto à implementação de programas de governo: em foco o Programa Nacional do Livro Didático. Educação \& Sociedade - Revista de Ciência e Educação, Campinas, a. XXI, n. 70, p. 159-170, 2000.

KOERNER, Konrad. Questões que persistem em Historiografia Linguística. Revista $d a$ ANPOLL, São Paulo, n. 2, p. 45-70, mai., 1996.

LE GOFF, Jacques. História e Memória. Trad. Bernardo Leitão et al. 4. ed. Campinas: Editora da Unicamp, 1996.

LEMOS, Daniel Cavalcante de Albuquerque. Tensões e disputas: os professores e os livros escolares no século XIX. e-hum - Revista Científica das áreas de História, Letras, Educação e Serviço Social do Centro Universitário de Belo Horizonte. Belo Horizonte, v. 3, n. 2, p. 15-28, 2010.

MILANI, Sebastião Elias. Historiografia-linguística de Ferdinand de Saussure. Goiânia: Kelps, 2011.

. Aspectos historiográficos-linguísticos do século XIX. Jundiaí: Paco Editorial, 2012.

. Historiografia linguística de Wilhelm von Humboldt: conceitos e métodos. Jundiaí: Paco Editorial, 2012b.

OLIVEIRA, João Batista Araújo et al. A política do livro didático. São Paulo: Unicamp, 1984.

ORLANDI, Eni Pulcinelli. Análise do discurso: princípios e procedimentos. Campinas: Pontes, 1999.

PILETTI, Claudino; PILETTI, Nelson. História da Educação: de Confúcio a Paulo Freire. São Paulo: Contexto, 2013.

RAZZINI, Márcia de Paula Gregório. Antologia Nacional de Fausto Barreto e Carlos de Laet (1895-1969): museu literário ou doutrina. 1992. Dissertação (Mestrado em Letras). Unicamp, Campinas, 1992.
O espelho da nação: a antologia nacional e o ensino de Português e de Literatura (1838- 1971). 2000. 442f. Tese (Doutorado em Letras). Unicamp, Campinas, 2000.

A Antologia Nacional e a ascensão do Português no currículo da Escola Secundária Brasileira. Educação em Revista - Revista da Faculdade de Educação da UFMG, Belo Horizonte, n. 38, p.13-45, jul. 2002.

ROSA, Helda Núbia. Historiografia Linguística da Gramática brasileira: a estrutura metalinguística e a participação na sociedade. 2011. Dissertação (Mestrado em Letras e Linguística) - Faculdade de Letras, Universidade Federal de Goiás, Goiânia, 2011.

SOARES, Magda. O livro didático como fonte para a história da leitura e da formação do professor-leitor. In: MARINHO, Marildes. (Org.) Ler e navegar: espaços e percursos da leitura. Campinas: Mercado das Letras: Associação de Leitura do Brasil, 2001. p. 31-76.

WITZEL, Denise Gabriel. Identidade e Livro Didático: movimentos identitários do professor de língua portuguesa. 2002. Dissertação (Mestrado em Linguística Aplicada). Universidade Estadual de Maringá, Maringá, 2002. 